\title{
Esophageal intramural pseudodiverticulosis with food impaction
}

\author{
Tan Attila MD, Norman E Marcon MD FRCPC
}

T Attila, NE Marcon. Esophageal intramural pseudodiverticulosis with food impaction. Can J Gastroenterol 2006;20(1):37-38.

\begin{abstract}
Esophageal intramural pseudodiverticulosis is a rare condition of unknown etiology originally described in 1960. It is characterized by multiple, flask-shaped outpouchings of pinhead size in the wall of the esophagus. Very small outpouchings on endoscopy and tiny collections of barium outside of the esophagus wall on esophagography are typical diagnostic findings. During the era of widespread endoscopic and radiological evaluation of esophageal disorders, approximately 200 cases were published in the literature. A 52-year-old man with esophageal intramural pseudodiverticulosis with food impaction is reported. The patient's symptoms of dysphagia resolved with endoscopic dilations and proton pump inhibitor therapy.
\end{abstract}

Key Words: Dyspepsia; Esophagus; Pseudodiverticulitis; Schatzki's ring

\section{CASE PRESENTATION}

A 57-year-old man of African descent presented to the emergency room with a food bolus impaction. The patient had been experiencing intermittent solid dysphagia for six months without any prior history of food impaction. The patient denied any heartburn, regurgitation, dyspepsia, abdominal pain and weight loss. He was not taking any prescription or over-thecounter medications. He had a history of alcohol abuse but denied smoking or ingestion of any caustic material. He had laparoscopic sigmoidectomy for stage 3 sigmoid cancer 18 months before presentation with the food impaction, for which he received six cycles of 5-fluorouracil and folinic acid therapy. A postsurgical computed tomography scan of the patient's thorax, abdomen and pelvis, with intravenous and oral contrast, was significant only for pancreatic calcifications within the head of the pancreas and a slightly irregular pancreatic duct consistent with chronic pancreatitis. Splenic vein thrombosis with multiple collaterals was noted at the splenic hilum. No mediastinal or hilar adenopathy were noted. Emergency upper endoscopy revealed a solid piece of meat at the distal esophagus, which was easily pushed into stomach. The esophageal mucosa did not have any ulceration or necrosis, but a Schatzki's ring was noted. The patient was discharged from the emergency room with daily proton pump inhibitor therapy. The patient was seen electively for a repeat upper endoscopy with dilation of the Schatzki's ring. Careful evaluation of the esophagus revealed a diffuse esophageal pit-like appearance suggestive

\section{Pseudodiverticulose oesophagienne intramurale avec bouchon de nourriture}

La pseudodiverticulose oesophagienne intramurale est une affection rare, d'étiologie inconnue, qui a été décrite pour la première fois en 1960. Elle se caractérise par une multitude de diverticules de la grosseur d'une tête d'épingle, en forme de fiole, qui se trouvent dans la paroi de l'œsophage. La présence de très petits diverticules à l'endoscopie et de minuscules amas de baryum à l'extérieur de la paroi de l'œesophage, à l'oesophagographie, est un signe diagnostique caractéristique. À l'époque où l'évaluation endoscopique et radiologique des troubles de l'œsophage était pratique courante, on a fait état d'environ 200 cas dans la documentation médicale. Voici l'histoire d'un homme de 52 ans, atteint de pseudodiverticulose oesophagienne intramurale avec bouchon de nourriture. Les symptômes de dysphagie sont disparus par la dilatation endoscopique de l'œsophage et par un traitement aux inhibiteurs de la pompe à protons. of pseudodiverticulosis (Figure 1) and a Schatzki's ring. A tear of the ring was noted following esophageal dilation up to $36 \mathrm{Fr}$. Esophageal biopsies showed squamous epithelium without any abnormality. An esophagogram confirmed the diagnosis of pseudodiverticulosis (Figure 2). The patient was dilated to $45 \mathrm{Fr}$ on another occasion. His dysphagia completely resolved with esophageal dilation and proton pump inhibitor therapy. He has been symptom free for nine months.

\section{DISCUSSION}

Esophageal intramural pseudodiverticulosis (EIPD) is an uncommon condition characterized by flask-like outpouchings with segmental or diffuse involvement of the esophagus and is frequently associated with esophageal radiological narrowing $(1,2)$. In the largest retrospective review of esophageal radiological examinations, this condition was diagnosed in $0.15 \%$ of patients (3). EIPD occurs at any age; however, it is most commonly observed in the sixth and seventh decade of life (2). Postmortem examinations revealed that pseudodiverticula are, indeed, dilated excretory ducts of the esophageal submucosal glands (4,5). Although etiology and pathogenesis of this rare condition have been obscure, obstruction of ducts by inflammatory material, mucus and desquamated epithelium was postulated as the cause of ductal dilation (6). The presence of chronic esophageal inflammation in autopsies of patients with EIPD suggests that this condition may be a sequela of esophagitis (5). Despite esophagitis being relatively common in endoscopic

Division of Gastroenterology, Centre of Therapeutic Endoscopy and Endoscopic Oncology, University of Toronto, St Michael's Hospital, Toronto, Ontario

Correspondence and reprints: Dr Norman E Marcon, St Michael's Hospital, 16-062 Cardinal Carter Wing, 30 Bond Street, Toronto, Ontario

M5B 1W8. Telephone 416-864-3092, fax 416-864-5993, e-mail Norman.marcon@utoronto.ca

Received for publication June 25, 2005. Accepted July 14, 2005 


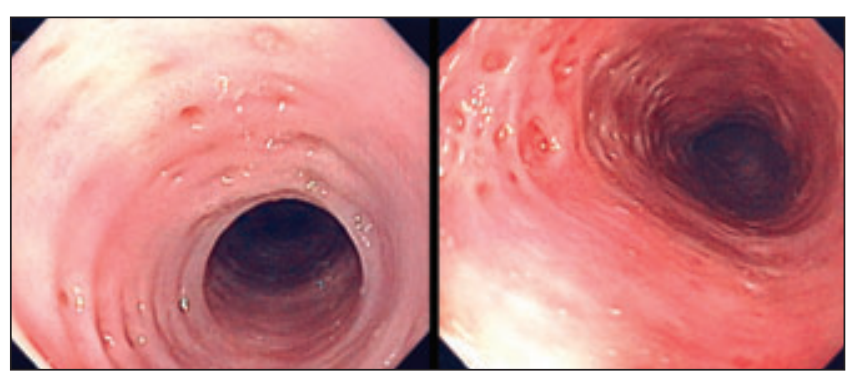

Figure 1) Esophagoscopy showing pit-like appearance typical for intramural pseudodiverticulosis

practice, it is unknown why EIPD is so rare. Our patient started to have dysphagia after chemotherapy, but we have not identified any literature on the etiological correlation between chemotherapy and EIPD. EIPD has been reported with gastroesophageal reflux, strictures, webs, herpes or candida esophagitis and esophageal neoplasm $(2,3,7,8)$. Although esophageal motility disorders, such as irregular tonic contractions, tertiary contractions and aperistalsis are commonly reported (2), the causative correlation is not clear. Dysphagia is the most common symptom, which may be acute or chronic $(9,10)$. The most effective therapy is dilation of strictures and treatment of esophagitis.

Our knowledge of the long-term outcome of this condition is limited. On rare occasions, pseudodiverticula have disappeared, but in the majority of cases, visible pseudodiverticula persisted despite symptomatic relief $(9,10)$. Although EIPD has been traditionally viewed as a benign condition, a retrospective review of esophagograms at Tulane University (Louisiana, USA) revealed a significantly higher prevalence of this condition in patients with esophageal carcinoma (11).

\section{REFERENCES}

1. Mendl K, McKay JM, Tanner CH. Intramural diverticulosis of the oesophagus and Rokitansky-Aschoff sinuses in the gall bladder. Br J Radiol 1960;33:496-501.

2. Sabanathan S, Salama FD, Morgan WE. Oesophageal intramural pseudodiverticulosis. Thorax 1985;40:849-57.

3. Levine MS, Moolten DN, Herlinger H, Lauger I. Esophageal intramural pseudodiverticulosis: A reevaluation. Am J Roentgenol 1986;147:1165-70.

4. Umlas J, Sakhuja R. The pathology of esophageal intramural pseudodiverticulosis. Am J Clin Pathol 1976;65:314-20.

5. Medeiros LJ, Doos WG, Balogh K. Esophageal intramural pseudodiverticulosis: A report of two cases with analysis of similar, less extensive changes in "normal" autopsy esophagi. Hum Pathol 1988;19:928-31.

6. Kataoka H, Higa T, Koono M. An autopsy case report of diffuse esophageal intramural pseudodiverticulosis. Acta Pathol Jpn 1992;42:837-40.

7. Price J, Gordon PA, Ng VK. Esophageal intramural pseudodiverticulosis associated with cervical esophageal web. Dysphagia 1988;3:49-50.

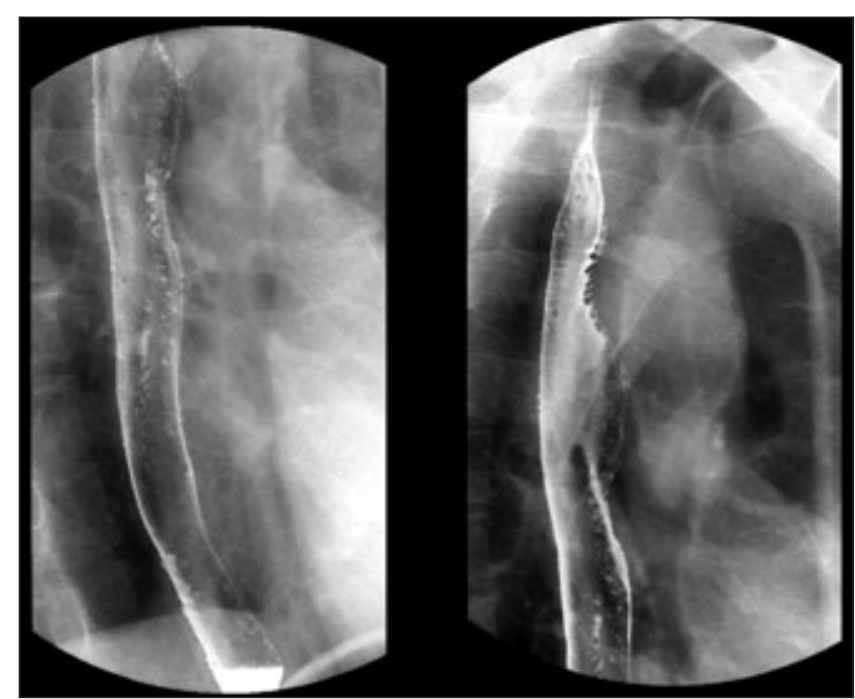

Figure 2) Esophagoscopy showing tiny collections of barium outside the wall of the esophagus

Long-term follow-up of these patients will determine the need for periodic surveillance. Peridiverticulitis is a rare complication of this benign condition $(12,13)$.

In summary, the present report describes a patient with diffuse EIPD who presented with food bolus impaction due to Schatzki's ring. His dysphagia completely resolved with endoscopic dilations and acid suppression with proton pump inhibitor therapy, but his EIPD persisted. It appeared that his dysphagia was secondary to Schatzki's ring and EIPD was an incidental finding. There is likely no cause and effect relationship between both conditions, but both of them probably share a similar cause - gastroesophageal reflux disease.

8. Muhletaler CA, Lams PM, Johnson AC. Occurrence of oesophageal intramural pseudodiverticulosis in patients with pre-existing benign oesophageal stricture. Br J Radiol 1980;53:299-303.

9. Hahne M, Schilling D, Arnold JC, Riemann JF. Esophageal intramural pseudodiverticulosis: Review of symptoms including upper gastrointestinal bleeding. J Clin Gastroenterol 2001;33:378-82.

10. Bruhlmann WF, Zollikofer CL, Maranta E, et al. Intramural pseudodiverticulosis of the esophagus: Report of seven cases and literature review. Gastrointest Radiol 1981;6:199-208.

11. Plavsic BM, Chen MY, Gelfand DW, et al. Intramural pseudodiverticulosis of the esophagus detected on barium esophagograms: Increased prevalence in patients with esophageal carcinoma. Am J Roentgenol 1995;165:1381-5.

12. Abrams LJ, Levine MS, Laufer I. Esophageal peridiverticulitis: An unusual complication of esophageal intramural pseudodiverticulosis. Eur J Radiol 1995;19:139-41.

13. Kim S, Choi CD, Groskin SA. Esophageal intramural pseudodiverticulitis. Radiology 1989;173:418. 


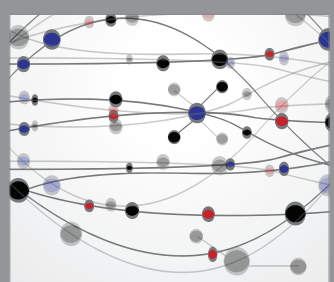

The Scientific World Journal
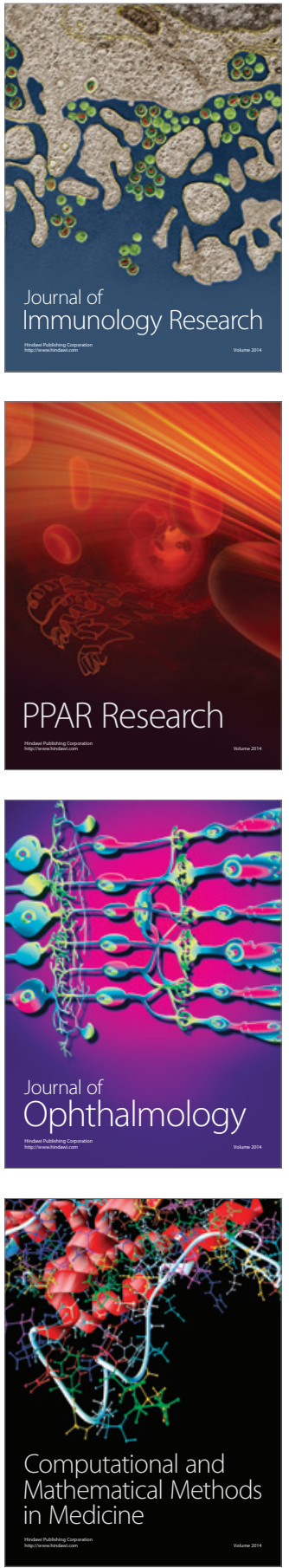

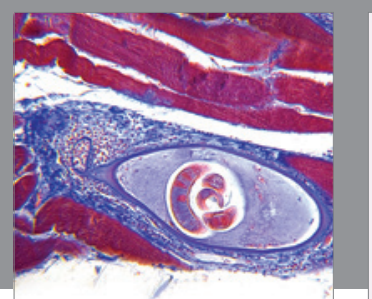

Gastroenterology Research and Practice

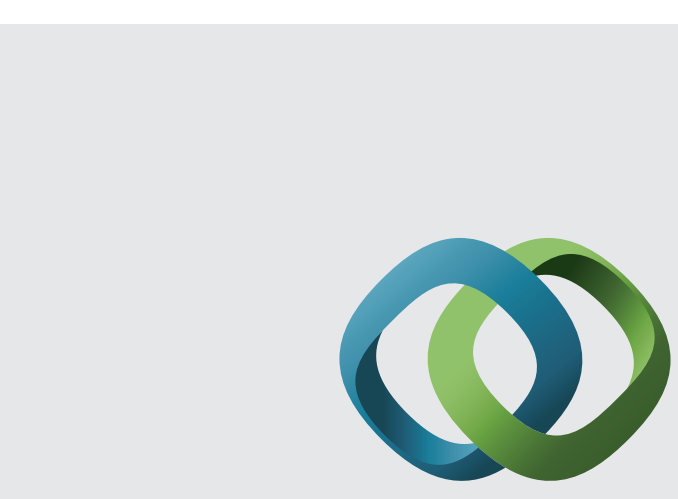

\section{Hindawi}

Submit your manuscripts at

http://www.hindawi.com
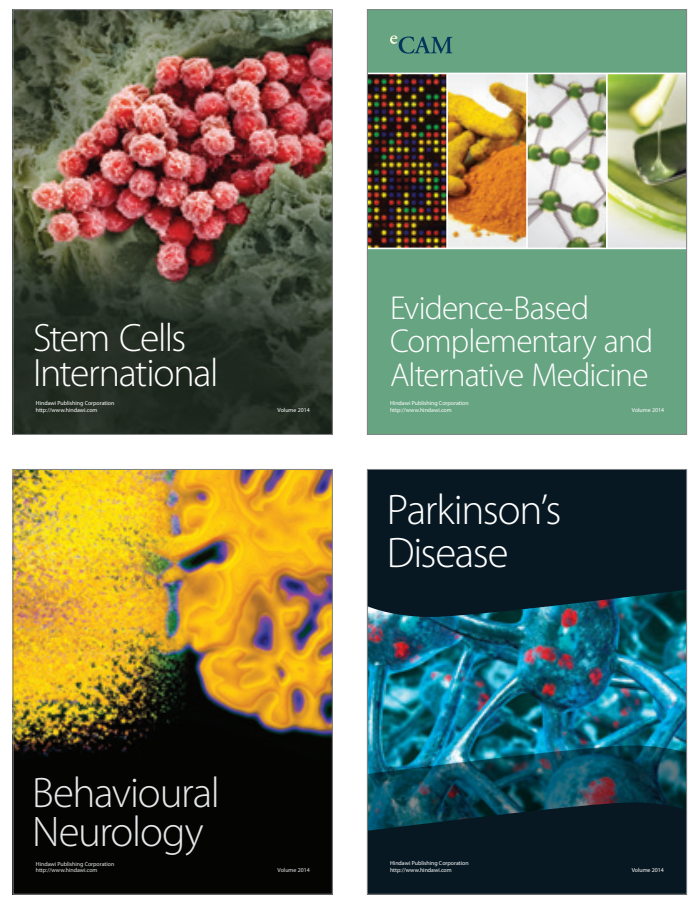
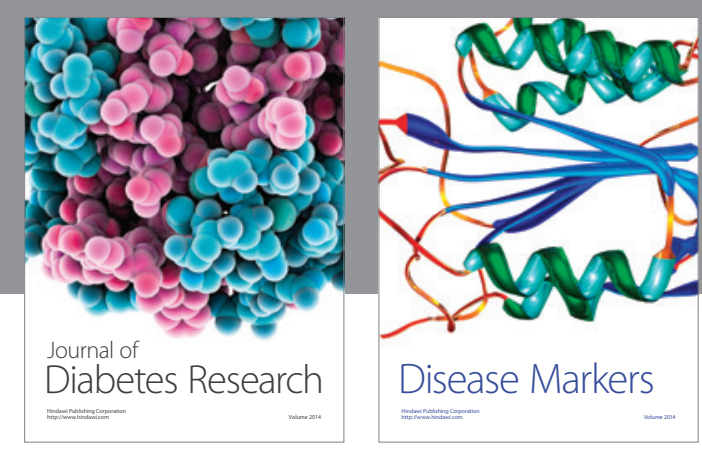

Disease Markers
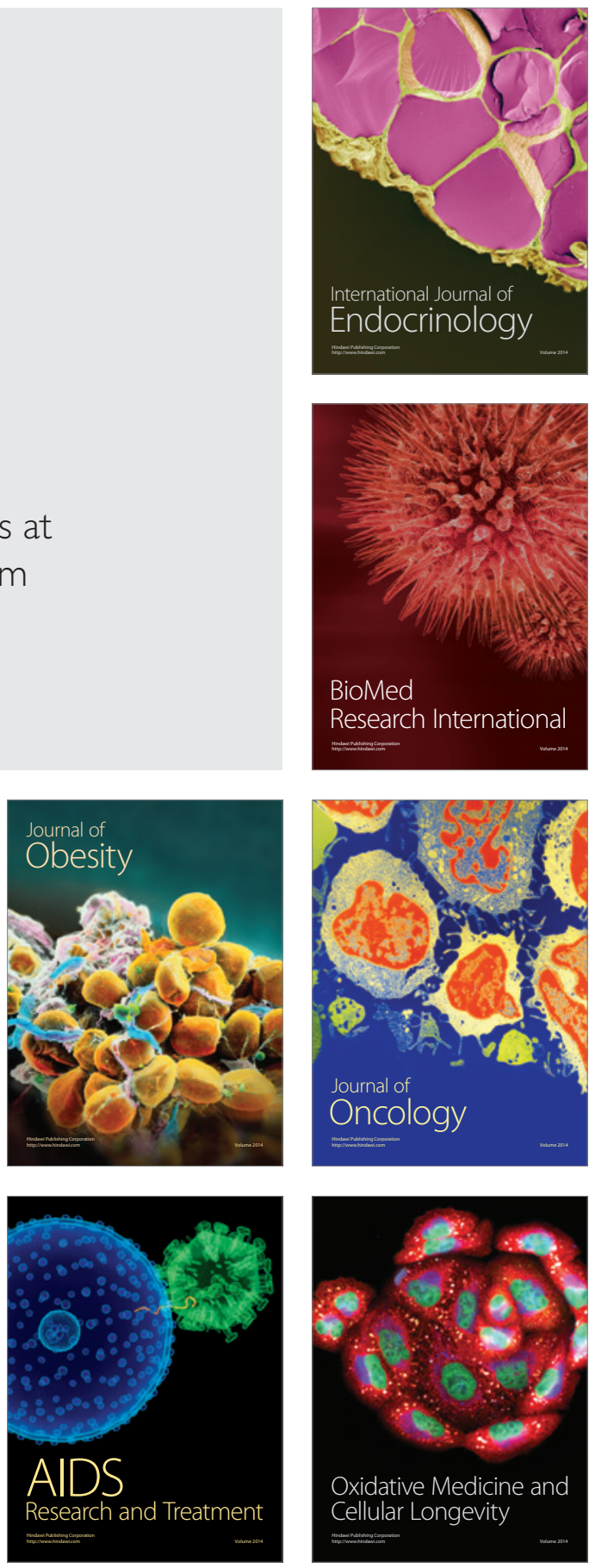